\title{
Functional Disorder of the Retina in Manganese-Deficient Japanese Quail Revealed by Electroretinography using a Contact Lens Electrode with Built-In Light Source
}

\author{
Kentaro ENDO' ${ }^{1)}$, Norihiko ITOH $^{2,3)}$, Seiya MAEHARA ${ }^{2)}$, Aya SHINOZAKI ${ }^{4}$, Tomohiro IMAGAWA ${ }^{4}$, \\ Masato UEHARA ${ }^{4)}$, Naoharu MIZUNO ${ }^{5)}$, Shoji SASAKI ${ }^{6)}$, Takeo HIRAGA ${ }^{1)}$ and Hiroki TERAOKA ${ }^{1) *}$ \\ ${ }^{1)}$ Departments of Toxicology, School of Veterinary Medicine and ${ }^{2)}$ Companion Animal Clinical Sciences, School of Veterinary Medicine, \\ Rakuno Gakuen University, Ebetsu, Hokkaido 069-8501, ${ }^{3)}$ Department of Ophthalmology and Visual Science, School of Medicine, \\ Yokohama City University, Yokohama, Kanagawa 236-0004, ${ }^{4}$ Department of Veterinary Anatomy, Faculty of Agriculture, Tottori \\ University, Tottori, Tottori 068-0945, 5) High-technology Research Center Rakuno Gakuen University, Ebetsu, Hokkaido 069-8501, \\ 6) Toxicology Unit, Global Preclinical Development Group, Global Pharmaceutical R\&D, Abbott Japan Co., Ltd., 1-9-9 Roppongi, \\ Minato-ku, Tokyo 106-8535, Japan
}

(Received 13 July 2007/Accepted 26 September 2007)

\begin{abstract}
Manganese deficiency results in neurological and skeletal defects, together with ultrastructural disarrangement of the retina in rats. Wild birds show a range of Mn concentrations in their tissues, including the liver, raising the possibility of Mn-related disorders in the wild. Electroretinography (ERG) provides a useful noninvasive approach to evaluate visual function. This method is especially useful in birds, as objective analysis of them is very difficult, while they have well-developed vision. In this study, we carried out a convenient and reliable ERG recording using a contact lens electrode with a built-in light source (LED electrode) of Japanese quail (Coturnix coturnix japonica) fed a Mn-deficient diet. After $10 \mathrm{~min}$ light adaptation, single-flash and flicker cone responses were reproducibly recorded to cause an intensity-dependent increase in amplitude of both a-wave and b-wave in single-flash ERG. Mn-deficient feeding markedly decreased the Mn concentration in the liver by almost half in 3 to 6 weeks, followed by body weight loss in 13 to 15 weeks. Implicit time of a-wave and b-wave cone response by single-flash stimulation was significantly delayed in quail with a Mn depletion from 3 to 6 weeks. Every cone response of the Mn-deprived quail had a tendency to decrease amplitude. The ultrastructure of cone photoreceptor cells was disorganized by Mn deficiency, including changes in outer segment discs of photoreceptor cells. These results suggest the essential role of $\mathrm{Mn}$ in the integrity of the retinal function of birds.

KEY WORDS: cone response, contact lens electrode, electroretinography, Japanese quail, manganese.
\end{abstract}

J. Vet. Med. Sci. 70(2): 139-144, 2008

Birds are highly visually dependent animals and possess superior visual capabilities to most other animals. This is the feature worthy of special mention among animals, many of which are dependent on olfactory functions, except primates, another visually dependent vertebrate. Electroretinography (ERG) is a valuable and non-invasive method for evaluation of retinal function. This is important especially as it is practically impossible to communicate with animals. Behavioral strategy is another technique to determine the visual function of animals. However, it is not easily performed and requires intense long-term effort for successful studies, especially for birds [2].

When ERG is performed using an external light source, there is a possible variation in the stimulus strength for each recording, depending on the light source, in particular the position, and distance between the light and the retina of the animal subject [9]. Recently, a contact lens electrode with a built-in high-luminance diode (LED electrode) has been developed for reliable and economical ERG recording. LED-electrodes have already been applied in the veterinary area to dogs to demonstrate their usefulness $[15,16]$.

Manganese $(\mathrm{Mn})$ is an essential trace element. $\mathrm{Mn}$ is

\footnotetext{
* Correspondence to: Dr. Teraoka, H., Department of Toxicology, School of Veterinary Medicine, Rakuno Gakuen University, Ebetsu, Hokkaido 069-8501, Japan.

e-mail: hteraoka@rakuno.ac.jp
}

involved in various biochemical systems as an enzyme activator and in metalloenzymes, such as pyruvate carboxylase, diamine oxidase, and superoxide dismutase (Mn-SOD) [3]. Clinical symptoms of Mn deficiency include neurological problems, as well as growth retardation, abnormal skeletal development, and loss of reproductive capacity [24]. Maternal Mn deficiency during pregnancy induces ataxia and skeletal abnormalities with high infant mortality $[7,11]$. Gong and Amemiya reported ultrastructural disarrangement in the retina of Mn-depleted rats [10]. Wild birds show a range of Mn concentration in their tissues such as that of the liver, suggesting the possibility of Mn-related disorders in the field [8].

In this study, we used an LED electrode for ERG recordings in Japanese quail (Coturnix coturnix japonica), which are a conveniently sized and commercially available experimental animals. Quail also live wild in the field throughout the world, including in Japan. We suggest a role for Mn in the retinal function of birds, showing that some ERG waves and the retinal ultrastructure were significantly affected by Mn depletion in Japanese quail.

\section{MATERIALS AND METHODS}

Male adult Japanese quail (Coturnix coturnix japonica) (6 to 20 weeks old) were obtained from Chouei Shouten 
(Tokyo, Japan) and were fed a custom designed diet mainly composed of corn starch, milk casein, and granulated sugar according to the Japanese feeding standard for poultry [1] supplied by CLEA Japan (Tokyo, Japan). Control and Mndeficient diets contained 54 ppm and 1 ppm Mn of dry weight, respectively. Distilled water was supplied ad libitum. The quail were handled and used for all experiments under the Laboratory Animal Control Guidelines of Rakuno Gakuen University (Ebetsu, Japan).

An ERG measuring instrument, a portable ERG LE-3000 (Tomey Corporation, Nagoya, Japan) was used as previously described [15]. This apparatus combines a stimulus instrument, amplifier, and recorder. The frequency band is from 0.3 to $300 \mathrm{kHz}$. ERG contact lens electrodes with built-in diode light sources were used as active electrodes (diamiter $5 \mathrm{~mm}$, base curve $3.2 \mathrm{~mm}$ : LED electrode, Mayo, Inazawa, Japan), and needle and plate-type electrodes were used for reference and earth, respectively. To avoid any possible effects from the circadian cycle (especially for bwaves) [18], all recordings were carried out in the afternoon (3 to 6 p.m.).

Intramusclar injections of urethane $(200 \mathrm{mg} / \mathrm{kg}$; Sigma, St. Louis, MO, U.S.A.) were given 5 min after ketamine hydrochloride (40 mg/kg, IM; Fuji Chemicals, Kawaguchi, Japan) and xylazine hydrochloride (4 mg/kg, IM; Bayer Yakuhin, Osaka, Japan) were used for general anesthesia. Although mydriasis is absolutely required for the recording of ERG, ocular application of either d-tubocurarine, tropicamide, or brominated pancuronium did not cause mydriasis at all, in spite of that it has been reported that these drugs are effective in some bird species, including pigeons, owls, and ostriches [9]. However, we found that one drop of pancuronium bromide (Mioblock 0.2\%; Organon Japan, Osaka, Japan) onto the cornea every 5 min fully dilated the pupil for $2 \mathrm{hr}$ only when the edge of the cornea was touched slightly with a very fine needle (NS type; Seirin, Shimizu, Japan). The quail showed normal oculopupillary reflex with no different features for several days after these treatments. We used this simple and effective procedure to induce mydriasis in this study. Quail were laid face down on a commercially available heater used to maintain the body temperature of small animals $\left(38\right.$ to $40^{\circ} \mathrm{C}$ ) during the procedures. After 10 min light adaptation, single-flash cone ERG (addition time 6, stimulation interval $1 \mathrm{sec}$ ) and $30 \mathrm{~Hz}$ cone flicker ERG (addition time 32) were recorded. The backlight was set as $42.1 \mathrm{~cd} / \mathrm{m}^{2}$ according to Rojas et al. [21-23], who used 35.7 $\mathrm{cd} / \mathrm{m}^{2}$ for $10 \mathrm{~min}$ with several bird species. To study the luminosity characteristics, stimulation intensities was varied from -1.18 to $0.46 \log \mathrm{cd} / \mathrm{m}^{2} / \mathrm{msec}$ with addition time of 8 and $3 \mathrm{sec}$ intervals.

To determine Mn concentration, livers were removed just after euthanasia with chloroform and were dried for $12 \mathrm{hr}$ at $80^{\circ} \mathrm{C}$ after storage in a freezer at $-20^{\circ} \mathrm{C}$. About $100 \mathrm{mg}$ of powdered sample was digested in $5 \mathrm{~m} l$ nitric acid $(70 \%$; Kanto Kagaku, Tokyo, Japan) and $1 \mathrm{~m} l$ perchloric acid (60\%; Kanto Kagaku, Tokyo, Japan) at $180-200^{\circ} \mathrm{C}$. Digested samples were diluted to $20 \mathrm{~m} l$ with ultrapure water in glass tubes. Measurement was carried out using a graphite furnace atomic absorption spectroscopy (AAnalyst 800, PerkinElmer, Wellesley, MA, U.S.A.). Recoveries were almost $100 \%$ when standard materials were used (human hair; National Institute for Environmental Studies (NIES) No. 13, NIES, Tsukuba, Japan). All specimens, including blanks, samples for a standard calibration curve, and standard materials, were measured simultaneously [25].

For electron microscopy, the posterior halves of eyes were fixed in a solution of $2 \%$ paraformaldehyde and $1 \%$ glutaraldehyde for $2 \mathrm{hr}$ or overnight at $4{ }^{\circ} \mathrm{C}$, and postfixed with $1 \% \mathrm{OsO}_{4}$ for $1.5 \mathrm{hr}$ [12]. After dehydration through a graded series of alcoholic solutions, pieces of retina were embedded in Epok-812 (Oken, Tokyo, Japan). Ultrathin sections were stained with aqueous uranyl acetate and lead citrate.

Results are presented as means \pm SEM. The significance of differences between experimental groups was determined by using a Tukey-Kramer test $(P<0.05)$.

\section{RESULTS}

Basic ERG responses in Japanese quail: After $10 \mathrm{~min}$ light adaptation, a single-flash stimulation $\left(3,738 \mathrm{~cd} / \mathrm{m}^{2} \times\right.$ $0.5 \mathrm{msec}$ ) was applied to record a cone ERG response (Fig. 1A). As with many animal species reported, an initial negative wave (a-wave) and following positive wave (b-wave) were reproducibly observed. The amplitudes of cone ERG were $63.58 \pm 4.35 \mu \mathrm{V}$ for the a-wave $(\mathrm{n}=25)$ and $151.46 \pm$ $10.40 \mu \mathrm{V}$ for the $\mathrm{b}$-wave $(\mathrm{n}=25)$. The implicit times were $18.25 \pm 0.80 \mathrm{msec}$ for an a-wave $(\mathrm{n}=25)$ and $40.66 \pm 2.44$ msec for a b-wave $(n=25)$. Both waves showed an intensitydependent increase in amplitude $\left(-1.18\right.$ to $0.46 \log \mathrm{cd} / \mathrm{m}^{2} /$ msec) (Fig. 2A, B).

To obtain a response more specific to cone cells, repetitive flash stimulation with high frequency (flicker ERG; $3,738 \mathrm{~cd} / \mathrm{m}^{2} \times 0.5 \mathrm{msec}, 30 \mathrm{~Hz}$ ) was applied to the Japanese quail (Fig. 1B). Reproducible repetitive positive currents were recorded in response to this stimulation. The amplitude of flicker ERG was $136.15 \pm 23.00 \mu \mathrm{V}(\mathrm{n}=18)$. The implicit time was $33.42 \pm 1.09 \mathrm{msec}(\mathrm{n}=18)$.

In contrast to the cone responses described above, rod response was rarely observed in Japanese quail, even after dark adaptation for $12 \mathrm{hr}$. Very small or no waves were observed upon weaker stimulation intensity $(-3.04 \log \mathrm{cd} /$ $\left.\mathrm{m}^{2} / \mathrm{msec}\right)$, while stronger stimulation $\left(-1.66 \log \mathrm{cd} / \mathrm{m}^{2} /\right.$ msec) evoked both a-waves and b-waves simultaneously, implying cone origin. This was the same for other dark adaptaion times (30 min, $4 \mathrm{hr}$ ), while time adopted for dark adaptation was $30 \mathrm{~min}$ for humans and dogs [16] and 2 or 4 $\mathrm{hr}$ for several diurnal and nocturnal birds [20-23].

Effects of Mn depletion on ERG: Body weight of quail was not affected by Mn deficiency after 3 to 6 weeks, but decreased dramatically by 13 to 15 weeks. Quail looked healthy for 3 to 6 weeks after Mn depletion, whereas they were markedly depressed with reduced motility around 13 to 15 weeks. On the other hand, Mn content in livers 
A

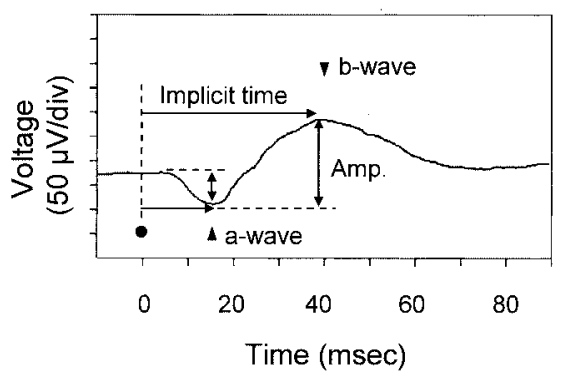

$\mathrm{B}$

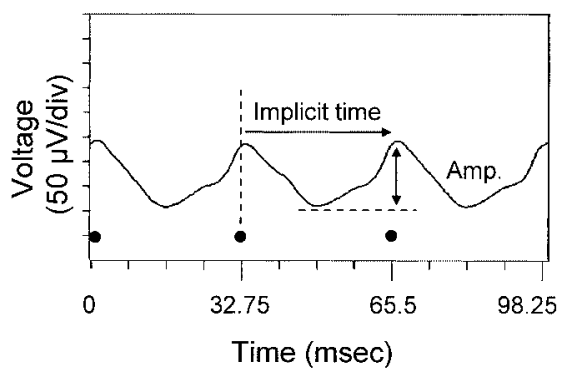

Fig. 1. Representative waveform of cone function ERG (A) and cone flicker ERG (B). Each circle point in $\mathrm{A}$ and $\mathrm{B}$ shows the flash stimulation. Arrows in horizontal directions and double arrows in vertical directions indicate implicit time and amplitude (Amp.) of the waves (a-wave, b-wave in A; flicker wave in B), respectively.

A

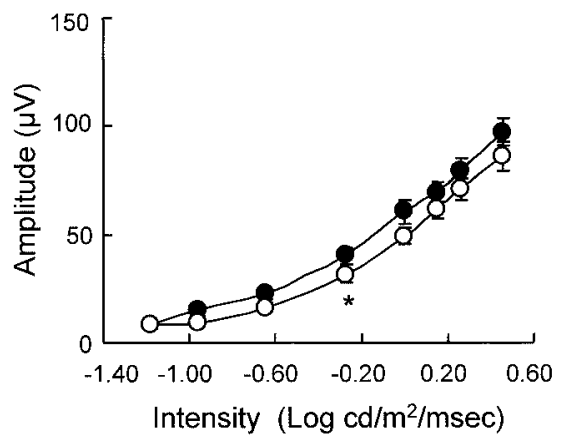

B

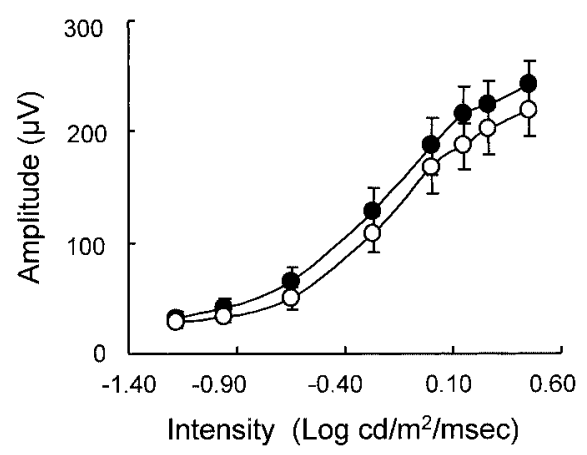

Fig. 2. Intensity dependency of the amplitude of a-waves (A) and b-waves (B) evoked by singleflash stimulation and the effects of Mn deprivation. Closed circles show control $(\mathrm{n}=8)$, and open circles show the data for quail fed with an Mn-deficient diet for 3 to 6 weeks $(n=10)$. ${ }^{*} P<0.05$.

decreased by half after Mn deprivation of 3 to 6 weeks (Fig. 3). We could not use serum for Mn determination in this study because of hemolysis of blood samples. Thus, quail with Mn deficiency of 3 to 6 weeks were used for ERG recording.

Mn deprivation caused a delay of implicit time of both waves by single-flash stimulation (Fig. 4). While a-waves, after relatively stronger stimulation, were markedly affected in Mn-deficient quail (Fig. 4A), the reverse was the case for b-waves (Fig. 4B). Amplitudes of both a- and b-waves also tended to decrease in Mn-deficient quail and a significant difference was recognized for $-0.25 \log \mathrm{cd} / \mathrm{m}^{2} / \mathrm{msec}$ for awaves (Fig. 2). A tendency toward inhibition of amplitudes in Mn-deficient quail was also observed for flicker stimulation.

Ultrastructural changes of retina by Mn deficiency: In the Mn-deficient quail, the position of the outer segment was irregular and the cytoplasm near the oil droplet was thicker than in controls (Fig. 5A and B). Many lysosomes (arrows in Fig. 5C) were observed in the retinal pigment epithelium, suggesting extensive phagocytosis of the degenerating outer

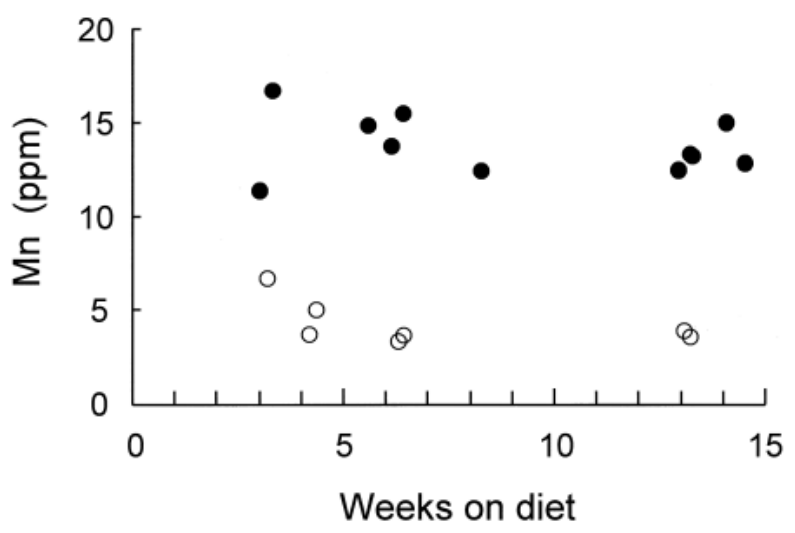

Fig. 3. Mn concentration in livers (ppm, dry weight) of quail fed with the control (closed circles) or Mn-deficient diets (open circles). Quail were fed with the diet for 3 to 15 weeks. 

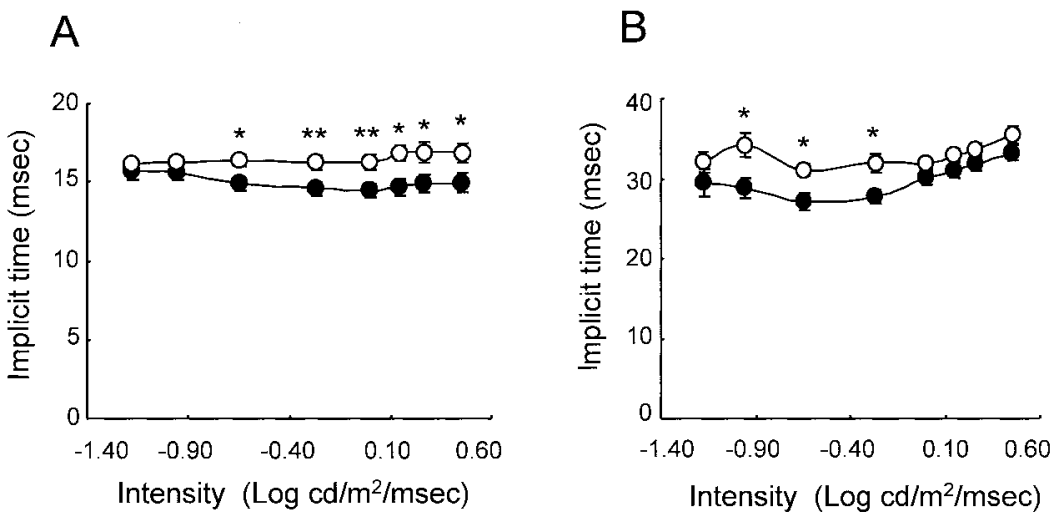

Fig. 4. Effect of Mn deficiency on implicit times of a-waves (A) and b-waves (B) evoked by different intensities of stimulation ( $\mathrm{Log} \mathrm{cd} / \mathrm{m}^{2} / \mathrm{msec}$ ). Closed circles show control $(\mathrm{n}=8)$, and open circles show the data for quail fed with a Mn-deficient diet for 3 to 6 weeks $(\mathrm{n}=10)$. $* P<0.05, * * P<0.01$.
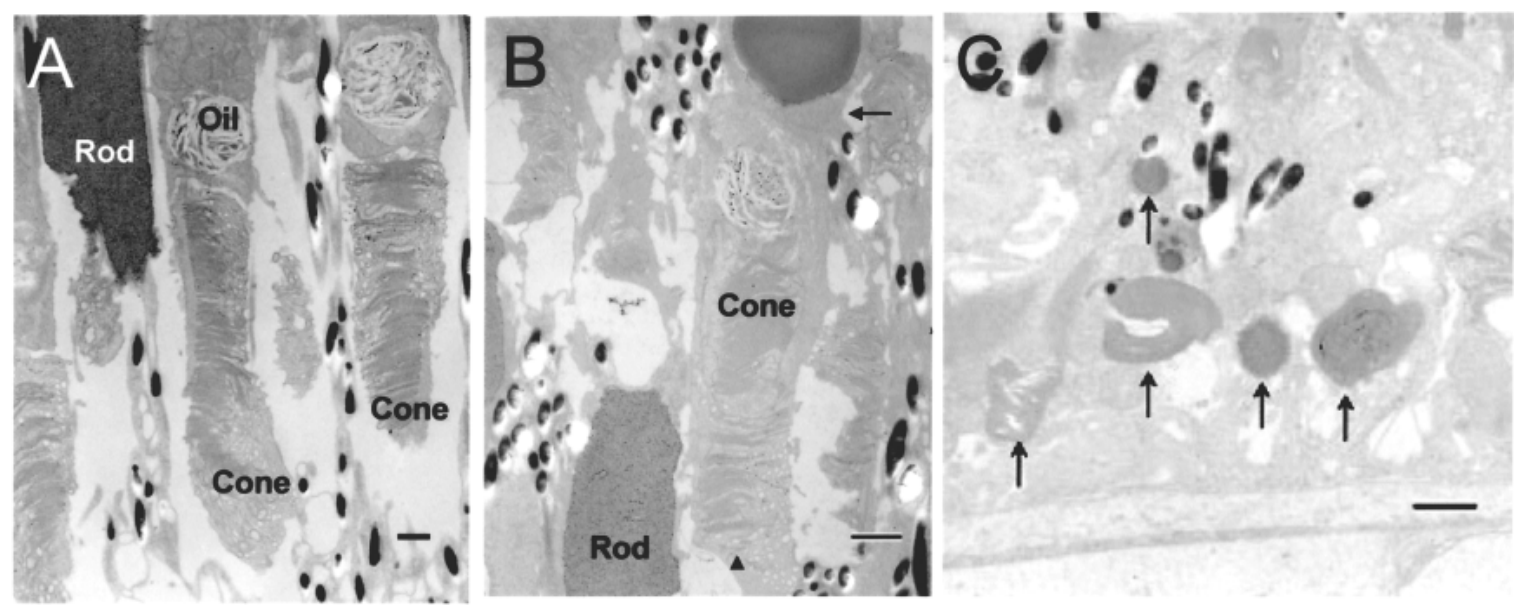

Fig. 5. Electron micrographs of the retinas of control quail (A) and Mn-deficient quail (B and C). In the Mn-deficient quail (B), the position of the outer segment of the cone photoreceptors was irregular (arrowhead), and the cytoplasm near the oil droplet (arrow) is thicker than that in the control (A). Many lysosomes (arrows) were visible in the retinal pigment epithelium in the Mndeficient quail (C). Scale bar $=1 \mu \mathrm{m}$.

segment of photoreceptors. There did not seem to be any particular change in mitochondria in spite of a marked increase in the number of mitochondria in the retina of $\mathrm{Mn}$ deficient rats [10].

\section{DISCUSSION}

The present experiments demonstrate the usefulness of the ERG recording system using an LED electrode for the study of retinal function in birds. Data with this recording system was sufficiently reproducible for statistical analysis of both implicit time and amplitude, particularly in ERG, by single- and flicker-flash stimulation under light adaptation. Using this system, we provided detailed information on cone ERG with Japanese quail, which are valuable as an experimental bird. Manglapus et al. [19] presented only a very small wave derived from rod cells of quail under dark adaptation. Similar to their observations, only a much smaller or no scotopic response could be detected in this study. McNeil et al. [20] reported that some birds active in darkness, such as the hermit thrush (Catharus guttatus) and American robin (Turdus migratorius), showed a relatively large scotopic response and that the amplitude was dependent on the proportion of rod to cone cells. Even for these nocturnal birds, the scotopic responses were relatively smaller with a much longer dark adaptation time compared to mammals [23]. Japanese quail may have a lower proportion of rod to cone cells [19].

We showed that the retinal electro-physiological function of quail was affected by Mn depletion in this study. Implicit time of both a- and b-waves stimulated by single flash under light adaptation was significantly delayed. This is the first 
functional support of a report of ultrastructural disarrangement provided by Gong and Amemiya [10]. Derangement caused by Mn deficiency was recognized long before obvious weight loss and clearly apparent changes, negating the possibly secondary systemic effects. Although the effect of Mn deficiency on weight loss or decreased weight gain appears to vary from species to species, decreased weight has been noted in some mammals [6] and hens [13]. Amplitude of both waves, except the response at stimulation of $0.25 \log \mathrm{cd} / \mathrm{m}^{2} / \mathrm{msec}$ for a-wave, was not significantly influenced in Mn-deficient quail, but a tendency toward inhibition was recognized. These findings indicate that implicit time under our condition is sensitive enough to detect visual damage by various harmful treatments when compared with amplitude.

It is noteworthy that a delay of implicit time by Mn depletion showed different intensity dependency between a- and b-waves. It is believed that photopic ERGs are generated by different types of retinal cells, although the contribution of each cell type is rather unclear, not only in birds, but also in mammals [26]. Generally, a-waves reflect the combined hyperpolarization of the photoreceptors, and b-waves represent the combined responses of the inner neural retina and the depolarization of Müller cells [5]. Although the ERG component of quail should be clarified, the present data could provide a clue to this if the damaged components could be found after further studies.

Gong and Amemiya [10] reported that photoreceptor cells showed karyopyknosis-like changes of nuclei and a decrease in the size and number of outer segments in rats fed a Mn-deficient diet for 12 months, followed by a complete loss of photoreceptor cells, and the inner nuclear layer nuclei came into direct contact with the retinal pigment epithelium for 18 months. Disarrangement of the outer segment of photoreceptor cells and extensive phagocytosis with lysosomes in the retinal pigment epithelium were observed in quail fed with a Mn-deficient diet in this study, while we could not observe either thinner retina, the disappearance of photoreceptor cells, or a marked increase in mitochondria in the photoreceptor inner segment, as described for Mn-deficient rats [10]. Although these inconsistencies could imply species differences, this might be due to the short period of Mn deprivation in the quail as Mn-deficient rats showed significantly decreased weight gain. Thus, it can be suggested that longer Mn deprivation may cause similar anatomical changes in quail, such as the photoreceptor loss observed in rats.

We cannot provide any suggestion as to why Mn depletion affected retinal function and ultrastructure. As a possible effect of Mn deprivation, Gong and Amemiya [10] discussed the activity of galactosyl transferase, an Mn-containing metalloenzyme, in relation to chondroitin sulfate synthesis, which results in decreased polymerization [14]. Another effect of Mn deprivation is a decrease in Mn-SOD activity, which is essential as a scavenging system for harmful free radicals in various tissues, including that of the retina $[4,17]$. It has been reported that a Mn-deficient diet decreases Mn-SOD activity in the kidneys and hearts of rats. Gong and Amemiya [10] discussed the etiology of the changes due to Mn deficiency in this context. However, like us, they did not present any supportive evidence. Further investigations are needed to clarify the detailed role of $\mathrm{Mn}$ in retinal function.

ACKNOWLEDGEMENTS. This work was supported by a grant-in-aid for Scientific Research (T.H.); a grant-in-aid for High Technological Research Center (Rakuno Gakuen University) from the Ministry of Education, Science, Sports and Culture of Japan (T.H.), and a grant-in-aid for Cooperative Research from Rakuno Gakuen University 2003-5 (T.H.).

\section{REFERENCES}

1. Agriculture, Forestry and Fisheries Research Council Secretariat, MAFF. 1997. Japanese Feeding Standard for Poultry. Central Association of Livestock Industry, Tokyo.

2. Cozby, P. C. 2004. Methods in Behavioral Research, 9th ed., McGraw-Hill, Hightstown.

3. Crowley, J. D., Traynor, D. A. and Weatherburn, D. C. 2000. Enzymes and proteins containing manganese: an overview. Met. Ions Biol. Syst. 37: 209-278

4. Dong, A., Shen, J., Krause, M., Akiyama, H., Hackett, S.F., Lai, H. and Campochiaro, P.A. 2006. Superoxide dismutase 1 protects retinal cells from oxidative damage. J. Cell Physiol. 208: $516-526$

5. Dowling, J. E. 1987. The Retina, Belknap Press, Cambridge.

6. Ellis, G. H., Smith, S. E. and Gates, E. M. 1947. Further studies of manganese deficiency in the rabbit. J. Nutr. 34: 21-31.

7. Erway, L., Harley, L. S. and Fraser, A. S. 1970. Congenital ataxia and otolith defects due to manganese deficiency in mice. J. Nutr. 100: 643-654.

8. Esselink, H., van der Geld, F. M., Jager, L. P., PosthumaTrumpie, G. A., Zoun, P. E. and Baars, A. J. 1995. Biomonitoring heavy metals using the barn owl (Tyto alba guttata): sources of variation especially relating to body condition. Arch. Environ. Contam. Toxicol. 28: 471-486.

9. Gelatt, K. N. 1999. Veterinary Opthalmology, Lippincott Williams \& Wilkins, Philadelphia.

10. Gong, H. and Amemiya, T. 1996. Ultrastructure of retina of manganese-deficient rats. Invest. Ophthalmol. Vis. Sci. 37: 1967-1974.

11. Hurley, L. S. 1981. Teratogenic aspects of manganese, zinc, and copper nutrition. Physiol. Rev. 61: 249-295.

12. Imagawa, T., Fujita, Y., Kitagawa, H. and Uehara, M. 1999. Quantitative studies of the optic nerve fiberlayer in the chicken retina. J. Vet. Med. Sci. 61: 883-889.

13. Klimis-Tavantzis, D. J., Kris-Etherton, P. M. and Leach, R. M. Jr. 1983. The effect of dietary manganese deficiency on cholesterol and lipid metabolism in the estrogen-treated chicken and the laying hen. J. Nutr. 113: 320-327.

14. Leach, R. M. Jr. 1971. Role of manganese in mucopolysaccharide metabolism. Fed. Proc. 30: 991-994.

15. Maehara, S., Itoh, N,, Itoh, Y., Wakaiki, S., Tsuzuki, K., Seno, T., Kushiro, T., Yamashita, K., Izumisawa, Y. and Kotani, T. 2005a. Electroretinography using contact lens electrode with built-in light source in dogs. J. Vet. Med. Sci. 67: 509-514.

16. Maehara, S., Osawa, A., Itoh, N., Wakaiki, S., Tsuzuki, K., Seno, T., Kushiro, T., Yamashita, K., Izumisawa, Y. and Kot- 
ani, T. 2005b. Detection of cone dysfunction induced by digoxin in dogs by multicolor electroretinography. Vet. Ophthalmol. 8: 407-413.

17. Macmillan-Crow, L. A. and Cruthirds, D. L. 2001. Invited review: manganese superoxide dismutase in disease. Free Radic. Res. 34: 325-336.

18. Manglapus, M. K., Iuvone, P. M., Underwood, H., Pierce, M. E. and Barlow, R. B. 1999. Dopamine mediates circadian rhythms of rod-cone dominance in the Japanese quail retina. $J$. Neurosci. 19: 4132-4141.

19. Manglapus, M. K., Uchiyama, H., Buelow, N. F. and Barlow, R. B. 1998. Circadian rhythms of rod-cone dominance in the Japanese quail retina. J. Neurosci. 18: 4775-4784.

20. McNeil, R., McSween, A. and Lachapelle, P. 2005. Comparison of the retinal structure and function in four bird species as a function of the time they start singing in the morning. Brain Behav. Evol. 65: 202-214.

21. Rojas, L. M., Mcneil, R., Cabana, T. and Lachapelle, P. 1999a. Diurnal and nocturnal visual capabilities in shorebirds as a function of their feeding strategies. Brain Behav. Evol. 53: 2943.

22. Rojas, L. M., Mcneil, R., Cabana, T. and Lachapelle, P. 1999b.
Behavioral, morphological and physiological correlates of diurnal and nocturnal vision in selected wading bird species. Brain Behav. Evol. 53: 227-242.

23. Rojas, L. M., Ramirez, Y., Mcneil, R., Mitchell, M. and Marin, G. 2004. Retina morphology and electrophysiology of two caprimulgiformes birds: The cave-living and nocturnal oilbird (Steatornis caripensis), and the crepusculary and nocturnally foraging common pauraque (Nyctidromus albicollis). Brain Behav. Evol. 64: 19-33.

24. Shils, M. E. and McCollum, E. V. 1943. Further studies on the symptoms of manganese deficiency in the rat and mouse. $J$. Nutr. 86: 1-19.

25. Teraoka, H., Kumagai, Y., Iwai, H., Haraguchi, K., Ohba, T., Nakai, K., Satoh, H., Sakamoto, M., Momose, K., Masatomi, H. and Hiraga, T. 2007. Heavy-metal contamination status of Japanese cranes (Grus japonensis) in East Hokkaido, Japan Extensive mercury pollution-. Environ. Toxicol. Chem. 26: 307-312.

26. Ueno, S., Kondo, M., Niwa, Y., Terasaki, H. and Miyake, Y. 2004. Luminance dependence of neural components that underlies the primate photopic electroretinogram. Invest. Ophthalmol. Vis. Sci. 45: 1033-1040. 